\title{
A Latent Class Growth Analysis of School Bullying and its Social Context: The Self- Determination Theory Perspective
}

Shui-fong Lam ${ }^{1}$, Wilbert Law ${ }^{1}$, Chi-Keung Chan ${ }^{2}$, Bernard P. H. Wong ${ }^{2}$, Xiao Zhang ${ }^{3}$

\begin{abstract}
Author Note
This research was supported by the Quality Education Fund of the Education Bureau in Hong Kong (Ref. No.: 2007/0115).

${ }^{1}$ Department of Psychology, University of Hong Kong

${ }^{2}$ Department of Counseling and Psychology, Hong Kong Shue Yan University

${ }^{3}$ Department of Early Childhood Education, Hong Kong Institute of Education
\end{abstract}

Correspondences concerning this paper should be addressed to Shui-fong Lam, Department of Psychology, University of Hong Kong, Pokfulam Road, Hong Kong, China. E-mail: lamsf@hku.hk. Telephone: (852) 3917-2388. Fax: (852) 2858-3518 


\title{
A Latent Class Growth Analysis of School Bullying and its Social Context: The Self- Determination Theory Perspective
}

\begin{abstract}
The contribution of social context to school bullying was examined from the self-determination theory perspective in this longitudinal study of 536 adolescents from three secondary schools in Hong Kong. Latent class growth analysis of the student-reported data at five time points from Grade 7 to Grade 9 identified four groups of students: bullies (9.8\%), victims (3.0\%), bullyvictims (9.4\%), and typical students (77.8\%). There was a significant association between academic tracking and group membership. Students from the school with the lowest academic performances had a greater chance of being victims and bully-victims. Longitudinal data showed that all four groups tended to report less victimization over the years. The victims and the typical students also had a tendency to report less bullying over the years but this tendency was reversed for bullies and bully-victims. Perceived support from teachers for relatedness significantly predicted membership of the groups of bullies and victims. Students with higher perceived support for relatedness from their teachers had a significantly lower likelihood of being bullies or victims. The findings have implications for the theory and practice of preventive interventions in school bullying.
\end{abstract}

Keywords: bullying, victimization, teacher support, school banding, self-determination theory 


\section{A Latent Class Growth Analysis of School Bullying and its Social Context: The Self- Determination Theory Perspective}

Bullying is considered as repeated acts of aggression against weaker victims who cannot easily defend themselves. This vicious kind of aggressive behavior is ubiquitous in schools and is known to have many negative consequences for both bullies and victims. Substantial literature has shown that being a bully is a significant predictor of low academic competence and externalizing problems including juvenile delinquency, substance abuse, affiliation with gangs, and even criminality in adulthood (Hazler, 1994; Holmes \& Brandenburg-Ayres, 1998; Nansel et al., 2001; Olweus, 1993), whereas being a victim is associated with poor academic performance and internalizing problems including low self-esteem, loneliness, social anxiety, and depression (Juvonen, Nishina, \& Graham, 2000). In general, bullying and victimization in schools are considered in two separate strands of literature. In recent years, researchers have begun to synthesize these two lines of research and emphasize a third group, the bully-victims, who are at risk of being both target and perpetrator of peer-directed aggression (e.g., Graham, Bellmore, \& Mize, 2006; Veenstra et al., 2005). Compared to bullies and victims, bully-victims are most troubled by problems in emotion regulation and impulse control (Schwartz, 2000). They constitute the most aggressive group of all and their aggression is both reactive and proactive (Salmivalli \& Nieminen, 2002).

The problem of bullying and victimization increases in late childhood, peaks in early adolescence, and tapers off in late adolescence (Bradshaw, Sawyer, \& O’Brennan, 2007; Williams \& Guerra, 2007). This problem is particularly acute during the transition from primary school to junior secondary school because it is a period of abrupt biological and social change. The rapid body changes in early adolescence coincide with dramatic changes in peer group 
composition and status that arise from the school transition. In face of the academic and social challenges in a new and impersonal environment, some adolescents may use social aggressive strategies to gain peer admiration and to advance in the peer social hierarchy (Neal, 2010). In a large scale survey with 15,686 students in Grades 6 through 10 in the U.S. (National Institute of Child Health and Human Development, 2001), 13\% of the participants reported bullying other students, $11 \%$ were victims of bullying, and $6 \%$ were identified as both victims and perpetrators of bullying. This representative sample revealed that $30 \%$ of the adolescents were involved in school bullying. The prevalence rates of bullies, victims, and bully-victims in early adolescence are indeed alarming to educators. Therefore, research and intervention programs that target this age group receive the most attention.

To develop and implement effective preventive interventions, researchers need to understand the various factors that may influence school bullying. Cook, Williams, Guerra, Kim, and Sadek (2010) point out that there is an overlooked aspect in the research on bullying and victimization because the emphasis of previous studies has been mainly on individual-level predictors. They argue that bullying occurs in a social context and that, without a social context, repeated aggressive acts toward others are impossible. Therefore, studying various aspects of the social context in which school bullying occurs is essential. This premise is supported by many researchers (e.g., Bradshaw \& Johnson, 2011; Hong \& Espelage, 2012), and remains the goal of the current project.

\section{Social Context}

Human development occurs in a nested arrangement of systems, each contained within the next (Bronfenbrenner, 1977). The most immediate systems in which a human organism develops are the microsystems (e.g., school, family, and workplace). As school bullying is 
defined as taking place in school, it is a corollary that school is the most influential microsystem for bullying. One objective of the present study is to examine whether school banding or academic tracking is associated with student involvement in peer aggression in Hong Kong secondary schools. Hong Kong offers a unique and interesting platform to study the influences of school banding on bullying because of its segregation policy in the allocation of secondary school places. Hong Kong students are entitled to a free and universal basic education from Grade 1 to 12 . When they complete primary school (Grade 1 to 6 ), they will move on to secondary school (Grade 7 to 12). Which secondary schools they will go to is determined by the Secondary School Places Allocation System (Education Bureau, n.d.). This system assigns students to three equally sized bands within each school district according to their school performances in Grades 5 and 6. To adjust for school differences, the classification of each student is weighted by the average test scores of his/her alumni in the Pre-Secondary Attainment Test, a standardized test that covers English language, Chinese language, and Mathematics. Schools are then assigned students from more or less the same band. Band 1 schools take in the top 33\% of students whereas Band 3 schools take in the bottom 33\% according to academic performance.

In Hong Kong, between-school ability grouping is used as one of the means to cope with student diversity. Homogenous grouping is considered as a strategy for teaching students with different abilities or prior knowledge (Loveless, 1997). However, it is criticized for its labeling effect and negative impact on the self-esteem of low-ability students (Slavin, 1990). In response to the criticism, the Hong Kong government has reduced the number of bands from five to three since 2001 when there was a strong demand for education reform (Education Commission, 2001). There is no further reduction in the number of bands since then because many teachers and 
parents still think that between-school ability grouping policy is necessary for effective teaching. Despite the controversy, this policy in Hong Kong provides an excellent setting to examine the influences of school banding on bullying and victimization.

Research has shown that school banding is a significant predictor of problem behaviors among Hong Kong adolescents. Compared to students in Band 1 schools, students in Band 3 schools were more likely to engage in delinquent behaviors and to use alcohol/tobacco (P. K. Lam, 2010). On the other hand, students in Band 1 schools may suffer from high academic stress and low academic self-concept because of the little-fish-in-big-pond effect (Marsh, Kong, \& Hau, 2000). In a study using focus group interviews with secondary school students, Bibou-Nakou, Tsiantis, Assimopoulos, Chatzilambou, and Giannakopoulou (2012) found that academic competition and the pressure of academic achievement contributed significantly to the bullying discourse of the students' talk. Studying in academically selective schools may not be a blessing for the students who are struggling to reach high academic standards. The current investigation aimed to contribute to the literature on the effects of school banding, a dimension of school context, on school violence.

\section{Self-determination Theory Perspective}

Another important dimension for the study of school context is teacher influences. This dimension is universal to all schools around the world. Research has shown that teachers' involvement in their students’ academic and social lives is an influential factor that prevents bullying. It was found that student aggression was negatively related to teacher support and positively related to conflict with the teacher (Hughes, Cavell, \& Willson, 2001). It was also found that adolescents were less inclined to resort to aggression when they perceived that their teachers could effectively address conflict and victimization (Aceves, Hinshaw, Mendoza- 
Denton, \& Page-Gould, 2010). Teacher support constitutes an important aspect of school context. To better understand teacher support and its impact on school bullying, self-determination theory (SDT) (Ryan \& Deci, 2000) provides a very useful perspective.

SDT proposes that social context is important to individual functioning and well-being because it influences the satisfaction of three basic psychological needs: relatedness, autonomy, and competence. These three needs are considered to be innate and universal for all human beings (Ryan \& Deci, 2000). The need for relatedness refers to the need for being connected to others (Baumeister \& Leary, 1995), the need for autonomy refers to the need for experience of volition and self-endorsement of one's behavior (deCharms, 1968), and the need for competence refers to the need to master one's environment effectively and attain valued outcomes within it (White, 1959). Social context can be need-fulfilling or need-thwarting, yielding very different results in human development. If the socializing agents in an important context are supportive to children's need satisfaction for relatedness, autonomy, and competence, the children will grow and flourish. Particularly, children can develop into more socially adjusted and pro-social individuals who are less prone to bullying or being victimized. The rationale is that when children are less need-frustrated, they are less likely to engage in violent and inconsiderate behaviors. Furthermore, socially adjusted children are less inclined to display behaviors that may provoke negative peer interactions. In contrast, if the socializing agents are not supportive, the children's growth will be hampered. In the worst case scenario, if these socializing agents go further to thwart or frustrate their needs, the children will be at risk of malfunctioning and of psychopathology. They may become defensive, self-centered, irresponsible, and even violent to others (Vansteenkiste \& Ryan, 2013). 
Teachers are the most important socializing agents in the school context. We argue that their support of students' need satisfaction for relatedness, autonomy, and competence influences their students’ involvement in bullying and victimization. Although SDT has been used to examine how social context is related to well-being or maladjustment in a wide array of domains including achievement motivation (e.g., Vansteenkiste, Lens, \& Deci, 2006), addiction (e.g., Wild, Cunningham, \& Ryan, 2006), and relationships (e.g., La Guardia, Ryan, Couchman, \& Deci, 2000), it has not been used in research on school bullying. Therefore, another objective of the present study is to examine how teacher support for the three basic needs is related to school bullying.

\section{Overview of the Study}

The present study aimed to extend our knowledge about the relationship between bullying and two social contextual variables, school banding and teacher support for basic needs, based on five sets of data collected in three Hong Kong secondary schools. A longitudinal study was employed to track changes in bullying and victimization throughout junior secondary school years. Junior secondary school students are targeted because school bullying is most rampant in their age group. With latent class growth analysis (Muthén, 2004) of the longitudinal data across the junior secondary school years, the present study aimed at answering the following four sets of questions.

First, with reference to the self-reported bullying and victimization behaviors across the junior secondary school years, how many groups of students can be identified? Does latent class growth analysis validate the classification of bullies, victims, and bully-victims?

Second, what are the trends of development of these groups across the junior secondary school years? Do self-reported bullying and victimization behaviors peak in Grade 7 when 
students enter secondary school and decline over the years by Grade 9? Do different groups of students have different trajectories in bullying and victimization behaviors?

Third, what are the effects of school banding? How is school banding associated with student reports of bullying and victimization behaviors? Does school banding predict the membership of the different groups identified in the latent class growth analysis?

Fourth, with reference to SDT, is students’ perceived support from teachers for the needs of relatedness, competence, and autonomy associated with student reports of bullying and victimization behaviors? Does perceived teacher support for these needs predict the membership of the different groups identified in the latent class growth analysis?

This study was largely exploratory and no a priori hypotheses were made for the first three sets of research questions. However, we expected that perceived support of basic psychological needs would predict less bullying and victimization, converging with the existing literature on the link between basic psychological need fulfillment and better social adjustment.

\section{Method}

\section{Participants and Procedures}

The present study was part of a large-scale longitudinal project that examined the antecedents and consequences of student engagement in schools across the junior secondary school years from Grade 7 to Grade $9^{1}$. Students $(N=536)$ from three Hong Kong secondary schools were invited to participate in this study. The three schools came from each of the three school types (Band 1, Band 2, and Band 3) described above. The academic performance of the students as reflected in the Pre-Secondary Attainment Test was significantly different across the three schools $\left.F(2,533)=887.61, p<.001, \eta^{2}=.77\right)$. The average scores of this standardized test for the participants in the Band 1 school $(M=115.60, S D=5.14)$, the Band 2 school $(M=$ 
102.59, $S D=6.76)$, and the Band 3 school $(M=85.52, S D=7.64)$ were significantly different from one another in all the pair-wise comparisons. The participants in these three schools were tracked from the second semester of Grade 7 to the second semester of Grade 9. They were asked to provide responses towards the end of each semester throughout the period of investigation, totaling up to five time points of data collection (T1 to T5).

A total of 536 students were included in the present study, with 154 students from the Band 1 school (97 females and 57 males), 185 from the Band 2 school (89 females and 96 males), and 197 from the Band 3 school (75 females and 122 males). The mean ages of students at T1 for the three schools were $12.72(S D=.69), 12.73(S D=.72)$, and $12.98(S D=.79)$, respectively. Passive parental consent was obtained before the longitudinal study began. Parents were informed of the details of the study and their right to opt out if they wished to. Student assent were also obtained before each administration of the questionnaire ${ }^{2}$. Students were asked to complete a questionnaire in their schools at the end of each semester. The questionnaire included measures of bullying, victimization and perceived teacher support for relatedness, autonomy, and competence. This data collection procedure was approved by the Human Research Ethics Committee at the corresponding author's institution.

\section{Measures}

Bullying. This was measured by a seven-item scale on peer aggression, including relational and physical aggression (Hill \& Werner, 2006). Students were required to indicate how often they engaged in different aggressive behaviors over the past semester. The sample items were "How often in the past semester did you exclude someone you didn’t like from group activities?”, and “How often in the past semester did you hit someone because you didn’t like what that person said or did?” Students were required to rate these aggressive behaviors on a 5- 
point Likert scale $(1=$ never, 2 = at least once every 3 months, $3=$ at least once a month, $4=a t$ least once $a$ week, and 5 = at least once a day). The mean of the seven items indicated the frequency of bullying behaviors. Table 1 includes the reliabilities of this scale together with the scales below.

Victimization. This was measured by a seven-item scale adapted from Hill and Werner (2006). Students were required to indicate how often they were the victims of aggression over the past semester. The seven items were identical to the measure of bullying except that the question stem was changed to “How often in the past semester did someone...?” Students were required to rate these items on the same 5-point Likert scale as that used for the measure of bullying. The mean of the seven items indicated the frequency of victimization behaviors.

Perceived support for relatedness. This was measured by the three items of the "Caring Adult Relationships in School Scale” in the California Healthy Kids Survey (WestEd, 2000). The three items measured how much students felt that there were teachers in their schools who cared about them, were kind to them, and listened to them when they had something to say. Students indicated their agreement to the three items on a 5-point Likert scale ranging from 1 (strongly disagree) to 5 (strongly agree). The mean of the three items indicated the levels of support for relatedness experienced by students. High scores indicated high levels of perceived support for relatedness.

Perceived autonomy support. This was measured by the four items of the "Autonomy" subscale of the "Motivating Instructional Contexts Inventory” (MICI; S.-f. Lam, Pak, \& Ma, 2007). Students were required to indicate the extent to which they perceived that they had teachers granting autonomy to them (e.g., "Teachers let us choose exercises that match our individual interests”). Students were required to indicate how many of their teachers adopted 
these teaching strategies on a 5-point Likert scale (1 = none, 2 = a few, 3 = half, $4=$ a majority, and $5=a l l)$. The mean of the four items indicated the levels of autonomy support experienced by students. High scores indicated high levels of perceived autonomy support.

Perceived competence support. This was measured by the four items of the "Challenge" subscale of the MICI. Students were required to indicate the extent to which they perceived they had teachers making an effort to ensure their mastery of learning tasks (e.g., “Teachers assign homework to students according to their abilities and academic levels”). Students were required to indicate how many of their teachers adopted these teaching strategies on a 5-point Likert scale (1 = none, 2 = a few, 3 = half, $4=$ a majority, and $5=$ all $)$. The mean of the four items indicated the levels of competence support experienced by students. High scores indicated high levels of perceived competence support from teachers.

\section{Strategy of Data Analysis}

Latent class growth modeling was employed to analyze the bullying and victimization data from five time points using the Mplus Version 6.0 package (Muthén \& Muthén, 1998-2010). Specifically, LCGM is a combination of the mixed-effects multilevel model and the latent class model in which random intercepts and slopes are continuous latent variables and trajectory classes are categorical latent variables (Muthén, 2001). LCGM is also the simplest mixture model for longitudinal data with the assumption that there is no within-class variability on the latent growth factors, and thus provides a clearer identification of latent classes and is less cumbersome in computation than more complex growth mixture modeling. In addition, LCGM is preferable to conventional growth models because it takes into account the unobserved heterogeneity among latent trajectory classes within a population (Jung \& Wickrama, 2008). In 
the present study, a parallel LCGM was fitted to the trend data of bullying and victimization behaviors reported by the participants.

Prior to specifying the full parallel LCGM model, we first fitted an unconditional oneclass latent growth curve model. Preliminary analyses found a linear trajectory fitted relatively better to the bullying and victimization trend data (RMSEA $=.099$ and .088 ) than a quadratic trajectory (RMSEA = .121 and .103). Then, two sets of LCGM were conducted to identify the number of latent classes separately for the bullying and victimization trend data. For either set of bullying or victimization data, a one-class model was first tested and then we fitted models with more classes (up to 5 classes). Multiple statistical indices and likelihood-based tests were used to determine the number of classes in LCGM (Bradshaw, Waasdorp, \& O’Brennan, 2013; Nylund, Bellmore, Nishina, \& Graham, 2010). Three often used model fit indices were computed in Mplus: Akaike’s information criterion (AIC), Bayesian information criterion (BIC), and sample size-adjusted Bayesian information criterion (SSA BIC). An LCGM was selected as the bestfitting model when the values of these indices begin to level off (Muthén, 2004). Additionally, the Lo-Mendell-Rubin (LMR) adjusted likelihood ratio test was adopted to compare the k and k1 class models. A significant $p$ value $(<.05)$ of this model comparison test suggested that the estimated class $(\mathrm{k})$ model significantly fits better than the one less class model $(\mathrm{k}-1)$. Furthermore, an entropy score was computed to examine the percentage of the sample accurately classified with a given LCGM model.

After determining the most appropriate number of classes for the trajectories of bullying and victimization, the next step was to establish a parallel LCGM to capture the co-occurrence of bullying and victimization over the three years of junior secondary school. This parallel LCGM model allowed us to identify the combination of groups based on the self-reported bullying and 
victimization behaviors over the five time points. Furthermore, the trends (intercepts and trajectories) of bullying and victimization for these combinations of groups were also computed. To address the research questions about the self-determination theory perspective, we included students’ perceived support from teachers for relatedness, autonomy, and competence at T1 as covariates and examined whether these three domains of perceived support can predict the membership of bullying and victimized groups. We also included gender (male as the reference group) and two school indicator variables (dummy-coded: Band 2 and Band 3 schools) as covariates to examine gender and school differences on bullying and victimization. The final parallel LCGM is presented in Figure 1. Lastly, post-hoc comparisons of the covariates were conducted to understand the characteristics of the classes identified in the final parallel LCGM.

The LCGM analyses included 536 students who had at least one data point in the measures of bullying and victimization. The number of respondents (non-respondents) in each of the five data points were 508 (28) at T1, 500 (36) at T2, 506 (30) at T3, 508 (28) at T4, and 478 (57) at T5. Overall, there were 179 missing data points out of the possible total of 2,680 (536 X 5) data points (6.7\%). Significant differences between respondents and non-respondents were found on school banding distribution (at T1-T4), on gender distribution (at T1 and T5), and on attainment scores (T1, T3-T5). Non-respondents were more likely to be in schools of lower banding, male, and have low attainment scores. An attrition analysis was conducted to assess the impact of longitudinal attrition. There is no evidence that missing data on the outcome variables resulted from the students' bullying and victimization behaviors at an earlier time point. Thus, the assumption of missing data at random (Long, 2012; Schafer \& Graham, 2002) held and the standard MAR approach was applied. The parameters of the models were estimated using the full information maximum likelihood (FIML) estimation with non-normality robust standard 
errors (Muthén \& Muthén, 1998-2010). Nevertheless, records with missing data on the covariates were excluded from the parallel LCGM analyses.

\section{Results}

\section{Descriptive Statistics}

Table 1 provides the descriptive statistics of gender, age, and the three SDT indicators at $\mathrm{T} 1$ as well as the average ratings of bullying and victimization form $\mathrm{T} 1$ to $\mathrm{T} 5$ for the three participating schools and the overall sample. The Band 1 school had significantly more female students (63.0\%) than the other two schools. The average age of students in the Band 3 school was slightly greater than that of students in the Band 1 and Band 2 schools. At T1, the Band 1 school had significantly higher scores on perceived teacher support for relatedness than the other two schools. However, students in the Band 3 school had significantly higher perceived autonomy and competence support than those in the Band 1 school. The average ratings of the Band 3 school on bullying were significantly higher than those of the Band 1 school across all five time points and were significantly higher than those of the Band 2 school at T1. In terms of victimization, the average ratings of the Band 3 school were significantly higher than those of the other two schools over the junior secondary school years.

\section{Identifying Latent Classes}

In response to the first and second sets of research questions, LCGM was conducted to unveil the number of bullying classes in our dataset. Table 2 contains the fit indices (i.e., AIC, BIC, SSA BIC, and LMR adjusted likelihood ratio test and its p-value) for the LCGM models with one through five classes for bullying (top panel) and victimization (bottom panel), respectively. Based on the results of the LMR likelihood ratio test, the best-fitting model (bolded in Table 2) is composed of two classes for the trajectory of bullying and two classes for the 
trajectory of victimization. Furthermore, inspection of scree plots of AIC, BIC, and SSA BIC found that the values began to level off at two classes (the elbow), indicating that a three-class model did not improve the fit. By the data from the bullying measure, $19.2 \%(n=96)$ of the sample was classified as bullies and by the data from the victimization measure, $12.4 \%(n=62)$ of students were classified as victims.

Once the number of classes from the trajectory of bullying and victimization were identified, we built the parallel LCGM with two classes of bullying and two classes of victimization. In reply to the first set of research questions about grouping, the parallel LCGM analyses identified four classes of students (see Table 3). The four groups were (1) bully-victims (9.4\%), (2) bullies (9.8\%), (3) victims (3.0\%), and (4) typical students (77.8\%).

In reply to the second set of research questions about the trends of development of these groups, Table 3 also shows the initial levels (i.e. intercepts) and changes (i.e. slopes) of the selfreported bullying and victimization behaviors for the four groups. To better illustrate the slopes, Figure 2 presents the changes of bullying and victimization from T1 to T5. The estimated average initial levels of bullying of the bully-victims (1.94) and bullies (1.92) at T1 were significantly higher than those of the two non-bully groups (victims and typical students). In addition, there was a significant positive growth (0.08) of bullying behaviors in these two groups, suggesting that the bullying behaviors of these two groups were getting more frequent over the junior secondary school years (Cohen’s d effect size estimates: Bully-victims vs. Typical = 0.99; Bullies vs. Typical = 0.93; Victims vs. Typical $=0.01)$. On the contrary, the bully-victims $(2.45)$ and victims (2.43) had significantly higher average initial levels of victimization at T1 than the non-victimized groups (bullies and typical students). For these bully-victims and victims, there was a significant decline ( -0.05 ) of victimization, implying that self-reporting as victims was 
becoming less frequent over the three years of junior secondary school (Cohen's d effect size estimates: Bully-victims vs. Typical $=1.87$; Bullies vs. Typical $=0.04$; Victims vs. Typical $=$ 2.11).

\section{Covariate Analyses}

To address the third set of research questions, concerning the effects of school banding, and the fourth set of questions, concerning the SDT perspective, the two school indicators (dummy-coded: Band 2 and Band 3 schools) and the three SDT indicators (perceived teacher support for relatedness, competence, and autonomy at T1) were added to the parallel LCGM as covariates. Research has indicated that gender is an important factor in school bullying and that male students are more likely to be involved (National Institute of Child Health \& Human Development, 2001). Therefore, gender was also included in the model as a covariate. First, we examined whether all the covariates can predict the membership of bullying and victimized groups. Next, we conducted post-hoc comparison analyses on the covariates to examine the characteristics of the four groups.

Table 4 summarizes the results of the conditional parallel LCGM in predicting the membership classification of bullying and victimized groups with the covariates. The results showed that there were significant gender differences in the likelihood of being identified as bullies or victims. The odds of being bullies or victims were significantly lower for female students than for male students. The chances for a female student to be classified as a bully and a victim were about five times (1/0.219) or four times (1/0.261) lower than for a male student, respectively. Regarding schools, there was no significant difference in the likelihood of students being classified as bullies between the three participating schools, whereas students in the Band 3 school had a significantly higher likelihood of being identified as victims. The odds for a 
student in the Band 3 school of being a victim were about 3.5 times higher than for a student in the Band 1 school.

Of the three SDT indicators, only perceived support for relatedness significantly predicted the membership of the bullying and victimized groups. Students with higher scores on perceived support for relatedness had a significantly lower likelihood of being bullies or victims. A unit increase in the score on teacher support for relatedness lowered the odds of being a bully by about 1.7 times (1/0.593) and reduced the odds of being a victim by about 2.1 times (1/0.473). Autonomy and competence support did not have any significant association with the membership classification of bullying and victimized groups.

Finally, post-hoc analyses of the covariates were conducted to explore the distinct characteristics of the four groups. The findings in Table 5 show that there were significant associations of group membership with school $\left(\chi^{2}=46.846, d f=6, p<.001\right)$ and with gender $\left(\chi^{2}\right.$ $=52.501, d f=3, p<.001)$. Male students and students in the Band 3 school were more likely to be classified as bully-victims and victims only and less than two-thirds of male students (64.8\%) and students in the Band 3 school (65.9\%) were typical students. In contrast, female students and students in the Band 1 school were more likely to be typical students ( $90.4 \%$ for female students and $88.3 \%$ for Band 1 students) and were the least likely to be in any of the problematic groups. Compared to the other two schools, the Band 2 school had a higher percentage of students in the bullies group. Nevertheless, this school still had high percentage of typical students (79.9\%).

The between-class comparison analyses of the three SDT indicators are summarized in Table 6. The results indicate that the scores on perceived teacher support for relatedness for bully-victims were significantly lower than those for the bullies and the typical students. There was no significant difference in support for relatedness between the bully-victims and the victims. 
These combined findings suggest that the bully-victims and the victims were associated with low scores on perceived support for relatedness. It is also noted that the average scores on autonomy and competence at T1 were similar across the four groups, indicating that there was very little variation in the perceived teacher support for autonomy or competence among these groups in the first year (Grade 7) of junior secondary school.

\section{Discussion}

The current research examined how students can be categorized by their reports of bullying and victimization behaviors, and how school context is associated with these categories. Utilizing longitudinal data from junior secondary school years in Hong Kong, four categories were identified: bully-victims, bullies, victims, and typical students. Overall, the four groups can be distinguished by their initial levels of bullying and victimization and any growth differences in these. The bully-victims had a significantly higher initial level of bullying and victimization, a progressive trend in bullying, and a decreasing trend in victimization. The bullies had a higher initial level with an accelerating trend in bullying behaviors but a lower initial level with a decelerating trend in being victimized. The victims had a higher initial level with a significantly faster decelerating rate in victimization but a lower initial level with a decrease in bullying. Finally, the typical students had a lower initial level with a slight decrease in both bullying and victimization behaviors.

School banding was a significant predictor of the groups in bullying and victimization. The school with the lowest academic standing had the highest percentage of students who were involved in bullying and victimization. It also had the highest percentage of bully-victims, which was the most problematic group. Perceived teacher’s support for relatedness significantly predicted the group membership of bullying and victimized groups. Post-hoc analysis showed 
that victims and bully-victims had a particularly low level of perceived relatedness need support from their teachers. This result partially supported our expectation that need satisfaction can be a protective factor against school bullying.

In the literature on bullying, it is often assumed that there are four groups of students: bullies, victims, bully-victims, and the typical students. This assumption is based on the simple crossing of the bullies and victims categories; however, empirical support is needed for such an assumption. The contribution of our study to the literature is the use of a person-centered approach (LCGM) to verify the number of students groups. The results of our study provided empirical support to the theoretical categorization, and allowed researchers more confidence in using this categorization. In addition, with the use of longitudinal measures, the present research also revealed the trajectories of the four latent classes. This helped us to see how bullying or victimization unfolded over time and the growth trajectories of each class.

Accurate mapping of the developmental trends of bullying and victimization can inform us about the need and timing of interventions. The literature has shown that bullying or victimization generally peaks at the beginning of middle school years and decreases over time (Williams \& Guerra, 2007) or remains stable across the middle school transition (Paul \& Cillessen, 2008; Pellegrini \& Bartini, 2000). This general picture does not account for the differences among groups. A contribution of the present study is the findings about the different trajectories of the four latent classes. Converging with the past studies, we found an overall trend of decreasing victimization across junior secondary school years; however, the degree of decrease was different between the groups. In particular, the victims and bully-victims were more victimized at the beginning and had a steeper drop in victimization than the bullies and typical students over the years. At the end of the junior secondary school year, the victims and 
bully-victims still suffered more from victimization than the typical students. The majority of the students (80.8\%) experienced a decrease in bullying; however, the bullies and bully-victims showed increasingly more bullying behaviors over the years. These alarming findings highlight the importance of intervention. The use of a person-focused analytical approach allowed us to discover such inter-individual differences in developmental trends that could otherwise be masked by a conventional variable-focused analytical approach.

School banding was linked with bullying and victimization. Another contribution of our research is its examination of the link between academic performance and bullying at the school system level. Although there was no significant difference in the odds of being a bully across the three schools, the odds of being a victim were higher in the Band 3 school. The asymmetry involved may be due to the fact that there is not necessarily a one-to-one mapping between bullies and victims. One bully can bully many victims. The same victim can be bullied by many bullies. In the present study, we found that the school that enrolled students with the lowest academic performance was more likely to have more victims and bully-victims. It is possible that grouping low academic performance students together may diminish the effectiveness of bullying interventions. Dishion, McCord, and Poulin (1999) proposed that intervention with peer groups that have problematic behaviors might actually result in an iatrogenic effect. Their argument is that seeing other deviant peers might reinforce the beliefs and behaviors of bullying. The current research might shed light on the policy of academic tracking. While most of the focus on academic tracking is on its effectiveness in instruction and achievement (Ross \& Harrison, 2006; Slavin, 1990), very little attention has been paid to non-academic outcomes. The current results suggest that academic tracking might entail a trade-off between academic 
effectiveness and bullying behaviors. In addition, bullying interventions are most in need for low academic tracking schools.

The current research has practical implications for interventions that aim to reduce bullying and victimization. Research has shown that commonly used methods such as suspension or detention are ineffective (Mayer, 1995; Sprague et al., 2001). Recently, interventions based on principles of behaviorism, such as setting clear contingency rules, and giving incentives for appropriate behaviors and punishment for rule-violations, have started to garner attention (e.g., Anderson \& Kincaid, 2005). Based on SDT, the current research suggests that intervention that targets strengthening teachers' support for the satisfaction of relatedness need could also be an effective means to reduce bullying. Specific strategies might include showing interest in the students, conveying that they are significant, and caring for them unconditionally. The I-Thou dialogue intervention developed by Kaplan and Assor (2012) represents a good example of utilizing such strategies. This intervention emphasized forming person-to-person bonds between teachers and students through deep meaningful dialogue. Teachers were encouraged to try to understand and support their students' needs. When students engaged in aggressive behaviors, teachers were asked to engage in dialogue that was characterized by open yet respectful expression of disagreement and by an attempt to find an optimal solution. The key is to be empathetic and taking the perspective of the students. Other interventions that might enhance teacher’s support for relatedness include Check \& Connect program in which closeness between intervention staff and students improves school engagement (Anderson, Christenson, Sinclair, \& Lehr, 2004), and the 4Rs model which promotes responsibility, respect, resourcefulness, and responsiveness in school (Corsini, 2007). 
Although teacher support for the satisfaction of the need in autonomy and competence did not significantly predict the membership of bullying and victimized groups, we should not lightly discard them as preventive factors. We suspect that the failure to detect such an association could be due to the method we used to measure teacher support for autonomy and competence needs. It was only measured in the context of classroom instruction; however, this might not capture the overall level of teacher support for these two needs. To rectify this problem, a better way would be measuring how teachers support autonomy and cultivates competence both inside and outside of the classroom. Once such research was conducted, we could answer whether teacher support for competence and autonomy needs are preventive factors of bullying.

In our study, one serendipitous finding warrants further investigation. Teacher support for the needs in autonomy and competence was the lowest in the Band 1 school, the school in which students had the highest academic ability. As discussed above, because of the little-fish-in-bigpond effect, many students in academically selective schools experience a low sense of academic competence. The learning environment of these schools is often described as highly competitive. In addition, it is common for teachers in these schools to use difficult learning materials for instruction that are beyond the students' proximal development zone (Cheung, 2013). As a result, these competitive and demanding practices might thwart the need for autonomy and competence. To alleviate the negative effects of the little-fish-in-big-pond phenomenon, one possible strategy is to de-emphasize competition and instead emphasize cooperative learning in the classroom (Cheng \& S.-f. Lam, 2007).

Before closing, there were some limitations of the current research to be considered. There was only one school per school banding in our sample. School banding effects in this research could be idiosyncratic to the specific schools that we sampled. Future replication studies 
should thus include more schools for each banding. In addition, socioeconomic status (SES) information was not available for the current study. Multiple reports have shown that low socioeconomic status was associated with higher odds of being bullied (Due et al., 2009; Jansen et al., 2012). Given that the Band 3 school in our study came from a relatively disadvantaged area of Hong Kong comparing to the other two participating schools (Hong Kong Census and Statistics Department, 2012), the differences in bullying/victimization could be attributed to low SES. To exclude this confounding factor, researchers shall also obtain information regarding the students' SES in future studies. Moreover, our research only investigated junior secondary school years, and future research could be extended to primary school and senior secondary school years in order to obtain a complete developmental picture of bullying behaviors. Last but not least, our results were based on self-reports. To increase the validity of the current results, future research would benefit from having multiple reports (e.g., from teachers, peers or third party observers) and behavioral data.

\section{Conclusion}

The current research contributes to the bullying literature in a variety of ways. In its contribution to theory, it verifies the four-category model of bullying and extends our knowledge of the trajectories of these groups. In addition, it utilizes a macro theory of human motivation self-determination theory - to provide a new perspective on the role of teachers' influence on bullying. In its contribution to methodology, it highlights the importance of the use of a more advanced statistical approach to capture the full dynamics of bullying. Last but not least, in its contribution to practice, it sheds light on an alternative to existing bullying intervention programs. School bullying remains an ongoing, worldwide, and complex problem. We believe research that is theory-driven and utilizes advanced methodologies will be essential in understanding the 
problem of bullying and the design of interventions that ensure the well-being and safety of our future generation. 


\section{References}

Aceves, M. J., Hinshaw, S. P., Mendoza-Denton, R., \& Page-Gould, E. (2010). Seek help from teachers or fight back? Student perceptions of teachers’ actions during conflicts and responses to peer victimization. Journal of Youth and Adolescence, 39, 658-669. doi: 10.1007/s10964-009-9441-9

Anderson, A. R., Christenson, S. L., Sinclair, M. F., \& Lehr, C. A. (2004). Check \& Connect: The importance of relationships for promoting engagement with school. Journal of School Psychology, 42, 95-113. doi: 10.1016/j.jsp.2004.01.002

Anderson, C. M., \& Kincaid, D. (2005). Applying behavior analysis to school violence and discipline problems: Schoolwide positive behavior support. The Behavior Analyst, 28, 4963.

Baumeister, R., \& Leary, M. R. (1995). The need to belong: Desire for interpersonal attachments as a fundamental human motivation. Psychological Bulletin, 117, 497-529. doi: 10.1037/0033-2909.117.3.497

Bibou-Nakou, I., Tsiantis, J., Assimopoulos, H., Chatzilambou, P., \& Giannakopoulou, D. (2012). School factors related to bullying: A qualitative study of early adolescent students. Social Psychology of Education, 15, 125-145. doi: 10.1007/s11218-012-9179-1

Bradshaw, C. P., \& Johnson, R. M. (2011). The social context of bullying and peer victimization: An introduction to the special issue. Journal of School Violence, 10, 107-114. doi: $10.1080 / 15388220.2011 .557145$

Bradshaw, C. P., Sawyer, A. L., \& O'Brennan, L. M. (2007). Bullying and peer victimization at school: Perceptual differences between students and school staff. School Psychology Review, 36, 361-382. 
Bradshaw, C. P., Waasdorp, T. E., \& O’Brennan, L. M. (2013). A latent class approach to examining forms of peer victimization. Journal of Educational Psychology. Advance online publication. doi: 10.1037/a0032091

Bronfenbrenner, U. (1977). Toward an experimental ecology of human development. American Psychologist, 32, 513-531. doi: 10.1037/0003-066X.32.7.513

Cheng, R. W.-y., \& Lam, S.-f. (2007). Self construal and comparison effects. British Journal of Educational Psychology, 77, 197-211. doi: 10.1348/000709905X72795

Cheung, K. T. (2013, October 2). Relentless demand for academic performance is destructive to children. Ming Pao, p. E8.

Cook, C. R., Williams, K. R., Guerra, N. G., Kim, T. E., \& Sadek, S. (2010). Predictors of bullying and victimization in childhood and adolescence: A meta-analytic investigation. School Psychology Quarterly, 25, 65-83. doi: 10.1037/a0020149

Corsini, R. (2007). Corsini's individual education: A democratic model. Group Dynamics: Theory, Research, and Practice, 11, 247-252. doi: 10.1037/1089-2699.11.4.247 deCharms, R. (1968). Personal causation. New York: Academic Press.

Dishon, T. J., McCord, J., \& Poulin, F. (1999). When interventions harm-Peer groups and problem behavior. American Psychologist, 54, 755-764. doi: 10.1037/0003066X.54.9.755

Due, P., Merlo, J., Harel-Fisch, Y., Damsgaard, M. T., Holstein, B. E., Hetland J., ... \& Lynch, J. (2009). Socioeconomic inequality in exposure to bullying during adolescence: a comparative, cross-sectional, multilevel study in 35 countries. American Journal of Public Health, 99, 907-914. doi: 10.2105/AJPH.2008.139303 
Education Commission. (2001). Reform of the education system in Hong Kong: Summary. Hong Kong: Government Printer. Retrieved from http://www.ec.edu.hk/eng/reform/index_e.html

Education Bureau (n.d.).General information on Secondary School Places Allocation (SSPA) System. Retrieved from http://www.edb.gov.hk/en/edu-system/primary-secondary/spasystems/secondary-spa/general-info/index.html

Graham, S., Bellmore, A. D., \& Mize, J. (2006). Peer victimization, aggression, and their cooccurrence in middle school: Pathways to adjustment problems. Journal of Abnormal Child Psychology, 34, 363-378. doi: 10.1007/s10802-006-9030-2

Hazler, R. J. (1994). Bullying breeds violence: You can stop it. Learning, 22, 38-41.

Hill, L. G., \& Werner, N. E. (2006). Affiliative motivation, school attachment, and aggression in school. Psychology in the Schools, 43, 231-246. doi: 10.1002/pits.20140

Holmes, S. R., \& Brandenburg-Ayres, S. J. (1998). Bullying behavior in school: A predictor of later gang involvement. Journal of Gang Research, 5, 1-6.

Hong, J. S., \& Espelage, D. L. (2012). A review of research on bullying and peer victimization in school: An ecological system analysis. Aggression and Violent Behavior, 17, 311-322. doi: 10.1016/j.avb.2012.03.003

Hong Kong Census and Statistics Department. (2012). Population and household statistics analyzed by district council district. Retrieved from http://www.censtatd.gov.hk/fd.jsp?file=B11303012012AN12B0100.pdf\&product_id=B1 130301\&lang=1 
Hughes, J. N., Cavell, T. A., \& Willson, V. (2001). Further support for the developmental significance of the quality of the teacher-child relationship. Journal of School Psychology, 39, 289-301.

Jansen, P. W., Verlinden, M., Dommisse-Van Berkel, A., Mieloo, C., van der Ende, J., Veenstra, R., ...\& Tiemeier, H. (2012). Prevalence of bullying and victimization among children in early elementary school: Do family and school neighborhood socioeconomic status matter? BMC Public Health, 12, 494. doi:10.1186/1471-2458-12-494

Jung, T. \& Wickrama, K. A. S. (2008). An introduction to latent class growth analysis and growth mixture modeling. Social and Personality Psychology Compass, 2, 302-317. doi: 10.1111/j.1751-9004.2007.00054

Juvonen, J., Nishina, A., \& Graham, S. (2000). Peer harassment, psychological adjustment, and school functioning in early adolescence. Journal of Educational Psychology, 92, 349-359. doi: 10.1037/0022-0663.92.2.349

Kaplan, H. \& Assor, A (2012). Enhancing autonomy-supportive I-Thou dialogue in schools: Conceptualization and socio-emotional effects of an intervention program. Social Psychology of Education, 15, 251-269. doi: 10.1007/s11218-012-9178-2

La Guardia, J. G., Ryan, R. M., Couchman, C. E., \& Deci, E. L. (2000). Within-person variation in security of attachment: A self-determination theory perspective on attachment, need fulfillment, and well-being. Journal of Personality and Social Psychology, 79, 367-384. doi: 10.1037/0022-3514.79.3.367

Lam, P. K. (2010). Values and problem behaviors in Hong Kong adolescents, ETD Collection for Wayne State University. Retrieved from http://digitalcommons.wayne.edu/oa_dissertations/97/ 
Lam, S.-f., Pak, T. S., \& Ma, W. Y. K. (2007) Motivating instructional contexts inventory. In P. R. Zelick (Ed.), Issues in the psychology of motivation (pp.119-136). Huppauge, NJ: Nova Science.

Long, J. D. (2012). Longitudinal data analysis for the behavior sciences using R. Thousand Oaks, CA: Sage.

Loveless, T. (1999). The tracking wars. Washington, D. C.: Brookings Institution Press.

Marsh, H. W., Kong, C.-K., \& Hau, K.-T. (2000). Longitudinal multilevel models of the bigfish-little-pond effect on academic self-concept: Counterbalancing contrast and reflectedglory effects in Hong Kong schools. Journal of Personality and Social Psychology, 78, 337-349. doi: 10.1037/0022-3514.78.2.337

Mayer, G. R. (1995). Preventing antisocial behavior in the schools. Journal of Applied Behavior Analysis 28, 467-478.

Muthén, B. O. (2001). Latent variable mixture modeling. In G. A. Marcoulides \& R. E. Schumacker (Ed.), New developments and techniques in structural equation modeling (pp. 1-34). Mahwah, NJ: Lawrence Erlbaum Associates.

Muthén, B. O. (2004). Latent variable analysis: Growth mixture modeling and related techniques for longitudinal data. In D. Kaplan (Ed.), The Sage handbook of quantitative methodology for the social sciences (pp. 345-369). Thousand Oaks, CA: Sage.

Muthén, L. K, \& Muthén, B. O. (1998-2010). Mplus user's guide (6 ${ }^{\text {th }}$ ed.). Los Angeles, CA: Author.

Nansel, T. R., Overpeck, M., Pilla, R. S., Ruan,W. J., Simons-Morton, B., \& Scheidt, P. (2001). Bullying behaviors among US youth: Prevalence and association with psychosocial adjustment. The Journal of the American Medical Association, 285, 2094-2100. 
National Institute of Child Health \& Human Development (2001). Bullying widespread in U.S. schools, survey finds. Retrieved from http://www.nichd.nih.gov/news/releases/bullying.cfm

Neal, J. (2010). Social aggression and social position in middle childhood and early adolescence: Burning bridges or building them? Journal of Early Adolescence, 30, 122-137. doi: $10.1177 / 0272431609350924$

Nylund, K., Bellmore, A., Nishina, A., \& Graham, S. (2010). Subtypes, severity, and structural stability of peer victimization: What does latent class analysis say? Child Development, 78, 1706-1722. doi: 10.1111/j.1467-8624.2007.01097.x

Olweus, D. (1993). Bullying at school: What we know and what we can do. Oxford: Blackwell.

Paul, J. J. \& Cillessen, A. H. N. (2003). Dynamics of peer victimization in early adolescence: Results from a four-year longitudinal study. Journal of Applied School Psychology 19, 25-43. doi: 10.1300/J008v19n02_03

Pellegrini, A. D. \& Bartini, M. (2000). A longitudinal study of bullying, victimization, and peer affiliation during the transition from primary school to middle school. American Educational Research Journal, 37, 699-725. doi: 10.2307/1163486

Ross, C. M., \& Harrison, P. T. (2006). Ability grouping. In G.G. Bear, K. M. Minke, \& A. Thomas (Eds.), Children's needs III: Development, problems, and alternatives (pp. 579588). Bethesda: NASP.

Ryan, R. M., \& Deci, E. L. (2000). Self-determination theory and the facilitation of intrinsic motivation, social development, and well-being. American Psychologist, 55, 68-78. doi: 10.1037/0003-066X.55.1.68 
Salmivalli, C., \& Nieminen, E. (2002). Proactive and reactive aggression among school bullies, victims, and bully-victims. Aggressive Behavior, 28, 30-44. doi: 10.1002/ab.90004

Schafer, J. L., \& Graham, J. W. (2002). Missing data: Our view of the state of the art. Psychological Methods, 7, 147-177. doi: 10.1037/1082-989X.7.2.147

Schwartz, D. (2000). Subtypes of victims and aggressors in children’s peer groups. Journal of Abnormal Child Psychology, 28, 181-192. doi: 10.1023/a:1005174831561

Slavin, R. E. (1990). Synthesis of research on grouping in elementary and secondary schools. In D. Hamachek (Ed.), Educational Psychology Reader: Toward the improvement of schooling (pp. 142-151). New York: Macmillan.

Sprague, J., Walker, H., Golly, A., White, K., Myers, D. R., \& Shannon, T. (2001). Translating research into effective practice: The effects of a universal staff and student intervention on indicators of discipline and school safety. Education \& Treatment of Children, 24, 495-511. Retrieved from http://search.proquest.com/docview/619828244?accountid=14548

Vansteenkiste, M., \& Ryan, R. M. (2013). On psychological growth and vulnerability: Basic psychological need satisfaction and need frustration as a unifying principle. Journal of Psychotherapy Integration, 23, 263-280. doi: 10.10170s0954579405050467

Vansteenkiste, M., Lens, W., \& Deci, E. L. (2006). Intrinsic versus extrinsic goal contents in self-determination theory: Another look at the quality of academic motivation. Educational Psychologist, 41, 19-31. doi: 10.1207/s15326985ep4101_4

Veenstra, R., Lindenberg, S., Oldehinkel, A. J., De Winter, A. F., Verhulst, F. C., \& Ormel, J. (2005). Bullying and victimization in elementary schools: A comparison of bullies, 
victims, Bully/Victims, and uninvolved preadolescents. Developmental Psychology, 41, 672-682. doi: 10.1037/0012-1649.41.4.672

WestEd (2000). California healthy kids survey. Los Alamitos, CA: WestEd.

White, R. W. (1959). Motivation reconsidered: The concept of competence. Psychological Review, 66, 297-333. doi: 10.1037/h0040934

Wild, T. C., Cunningham, J. A., \& Ryan, R. M. (2006). Social pressure, coercion, and client engagement at treatment entry: A self-determination theory perspective. Addictive Behaviors, 31, 1858-1872. doi: 10.1016/j.addbeh.2006.01.002

Williams, K. R., \& Guerra, N. G. (2007). Prevalence and predictors of internet bullying. Journal of Adolescent Health, 41, S14-S21. doi: 10.1016/j.jadohealth.2007.08.018 


\section{Footnotes}

${ }^{1}$ The scope of investigation of this longitudinal project was large and the variables in the questionnaire were many. In the present paper, only the variables related to bullying, victimization, and self-determination theory perspective were analyzed and presented.

${ }^{2}$ Applying this procedure, none of the parents opted out of the project and all youth assented to the procedures. 
Table 1. Demographic Characteristics, Descriptive Statistics and Internal Consistencies for SDT Indicators, Bullying and Victimization (T1 - T5) by School for the Sample

\begin{tabular}{|c|c|c|c|c|c|}
\hline & $\begin{array}{l}\text { Band } 1 \\
\text { School }\end{array}$ & $\begin{array}{l}\text { Band } 2 \\
\text { School }\end{array}$ & $\begin{array}{l}\text { Band } 3 \\
\text { School }\end{array}$ & Overall & $\begin{array}{c}\text { Cronbach's } \\
\text { Alpha }\end{array}$ \\
\hline \multicolumn{6}{|l|}{ Gender } \\
\hline$\overline{\text { Female }}$ & $97(63.0 \%)^{\mathrm{ab}}$ & $89(48.1 \%)^{\mathrm{a}}$ & $75(38.1 \%)^{b}$ & 261 (48.7\%) & - \\
\hline Male & $57(37.0 \%)^{a b}$ & $96(51.9 \%)^{a}$ & $122(61.9 \%)^{b}$ & 275 (51.3\%) & - \\
\hline Age at $\mathrm{T} 1$ & $12.72(0.69)^{\mathrm{b}}$ & $12.73(0.72)^{\mathrm{C}}$ & $12.98(0.79){ }^{\mathrm{bc}}$ & $12.81(0.73)$ & - \\
\hline \multicolumn{6}{|c|}{$\underline{\text { SDT Indicators }}$} \\
\hline$\frac{\text { at II }}{\text { Relatedness }}$ & $3.91(.64)^{\mathrm{ab}}$ & $3.70(.75)^{\mathrm{a}}$ & $3.53(.90)^{\mathrm{b}}$ & $3.70(.79)$ & .85 \\
\hline Autonomy & $2.70(.88)^{b}$ & $2.80(.81)$ & $2.97(.81)^{b}$ & $2.83(.83)$ & .81 \\
\hline Competence & $2.71(.74)^{b}$ & $2.81(.79)$ & $2.96(.76)^{b}$ & $2.83(.77)$ & .75 \\
\hline \multicolumn{6}{|l|}{ Bullying } \\
\hline $\mathrm{T} 1$ & $1.43(0.51)^{b}$ & $1.52(0.56)^{\mathrm{c}}$ & $1.84(0.77)^{\mathrm{bc}}$ & $1.60(0.65)$ & .85 \\
\hline $\mathrm{T} 2$ & $1.37(0.38)^{\mathrm{b}}$ & $1.44(0.50)$ & $1.55(0.59)^{\mathrm{b}}$ & $1.46(0.51)$ & .77 \\
\hline T3 & $1.44(0.49)^{\mathrm{b}}$ & $1.56(0.60)$ & $1.66(0.65)^{\mathrm{b}}$ & $1.56(0.59)$ & .85 \\
\hline $\mathrm{T} 4$ & $1.39(0.51)^{\mathrm{b}}$ & $1.49(0.52)$ & $1.61(0.70)^{\mathrm{b}}$ & $1.50(0.60)$ & .86 \\
\hline T5 & $1.36(0.60)^{\mathrm{b}}$ & $1.54(0.74)$ & $1.72(0.77)^{\mathrm{b}}$ & $1.55(0.72)$ & .92 \\
\hline \multicolumn{6}{|l|}{ Victimization } \\
\hline $\mathrm{T} 1$ & $1.36(0.57)^{\mathrm{b}}$ & $1.36(0.55)^{c}$ & $1.80(0.87)^{\mathrm{bc}}$ & $1.51(0.71)$ & .90 \\
\hline $\mathrm{T} 2$ & $1.25(0.48)^{\mathrm{b}}$ & $1.30(0.50)^{\mathrm{c}}$ & $1.56(0.71)^{\mathrm{bc}}$ & $1.38(0.60)$ & .86 \\
\hline T3 & $1.32(0.47)^{b}$ & $1.45(0.63)^{c}$ & $1.69(0.80)^{\mathrm{bc}}$ & 1.49 (0.67) & .89 \\
\hline $\mathrm{T} 4$ & $1.26(0.51)^{\mathrm{b}}$ & $1.38(0.55)^{c}$ & $1.57(0.76)^{\mathrm{bc}}$ & $1.41(0.63)$ & .89 \\
\hline T5 & $1.30(0.58)^{b}$ & $1.43(0.73)^{c}$ & $1.66(0.78)^{\mathrm{bc}}$ & $1.47(0.72)$ & .93 \\
\hline
\end{tabular}

Note:

$\mathrm{N}$ for Band 1 school = 154; $\mathrm{N}$ for Band 2 school = 185; $\mathrm{N}$ for Band 3 school = 197; $\mathrm{N}$ for Overall

$=536$

The numbers in the parentheses are standard deviations.

Within each row, pairs with the same superscripts indicate statistically significant differences at $\mathrm{p}<.05$ 
Table 2.

Comparison of Fit Indices for Latent Class Growth Models with 1-5 Classes for Bullying and Victimization in the Five Time Points

\begin{tabular}{|c|c|c|c|c|c|c|c|}
\hline $\begin{array}{l}\text { Number of } \\
\text { Classes }\end{array}$ & $d f$ & AIC & $\mathrm{BIC}$ & $\begin{array}{l}\text { Sample- } \\
\text { Size } \\
\text { Adjusted } \\
\text { BIC (SSA } \\
\text { BIC) }\end{array}$ & $\begin{array}{l}\text { Lo- } \\
\text { Mendell- } \\
\text { Rubin } \\
\text { (LMR) } \\
\text { Adjusted } \\
\text { LRT }\end{array}$ & $p$-Value & Entropy \\
\hline \multicolumn{8}{|c|}{ Bullying } \\
\hline 1 & 7 & 4651.140 & 4681.103 & 4658.883 & n.a. & n.a. & n.a. \\
\hline 2 & 10 & 4205.420 & 4248.223 & 4216.480 & 428.954 & 0.0030 & 0.847 \\
\hline 3 & 13 & 4129.295 & 4184.941 & 4143.674 & 77.985 & 0.4942 & 0.853 \\
\hline 4 & 16 & 4009.136 & 4077.622 & 4026.833 & 123.604 & 0.1255 & 0.811 \\
\hline 5 & 19 & 3964.423 & 4045.750 & 3985.438 & 152.561 & 0.4110 & 0.823 \\
\hline \multicolumn{8}{|c|}{$\underline{\text { Victimization }}$} \\
\hline 1 & 7 & 5078.375 & 5108.338 & 5086.118 & n.a. & n.a. & n.a. \\
\hline 2 & 10 & 4481.052 & 4523.856 & 4492.113 & 572.915 & 0.0352 & 0.931 \\
\hline 3 & 13 & 4313.969 & 4369.614 & 4328.348 & 164.360 & 0.0850 & 0.945 \\
\hline 4 & 16 & 4159.834 & 4228.320 & 4177.531 & 152.065 & 0.1682 & 0.909 \\
\hline 5 & 19 & 4113.786 & 4195.114 & 4134.802 & 49.425 & 0.5118 & 0.914 \\
\hline
\end{tabular}


Table 3.

Classification of Individuals based on Their Most Likely Latent Class Pattern

\begin{tabular}{|c|c|c|c|c|c|c|}
\hline $\begin{array}{l}\text { Latent Class } \\
\text { Membership }\end{array}$ & Counts & $\%$ & $\begin{array}{l}\text { Intercept } \\
\text { Bullying }\end{array}$ & $\begin{array}{l}\text { Trajectory } \\
\text { Bullying }\end{array}$ & $\begin{array}{l}\text { Intercept } \\
\text { Victimization }\end{array}$ & $\begin{array}{l}\text { Trajectory } \\
\text { Victimization }\end{array}$ \\
\hline Bully-victims & 47 & 9.38 & $\begin{array}{l}1.944^{\mathrm{bc}} \\
(0.012)\end{array}$ & $\begin{array}{l}0.081^{\mathrm{bc}} \\
(0.002)\end{array}$ & $\begin{array}{l}2.451^{\mathrm{ac}} \\
(0.018)\end{array}$ & $\begin{array}{l}-0.056^{\mathrm{ac}} \\
(0.0008)\end{array}$ \\
\hline Bullies & 49 & 9.78 & $\begin{array}{l}1.921^{\mathrm{de}} \\
(0.012)\end{array}$ & $\begin{array}{l}0.077^{\mathrm{de}} \\
(0.023)\end{array}$ & $\begin{array}{l}1.326^{\text {ad }} \\
(0.012)\end{array}$ & $\begin{array}{l}-0.002^{\text {ad }} \\
(0.0006)\end{array}$ \\
\hline Victims & 15 & 2.99 & $\begin{array}{l}1.405^{\mathrm{bd}} \\
(0.015)\end{array}$ & $\begin{array}{l}-0.018^{\text {bd }} \\
(0.0006)\end{array}$ & $\begin{array}{l}2.431^{\mathrm{df}} \\
(0.030)\end{array}$ & $\begin{array}{l}-0.055^{\mathrm{dt}} \\
(0.0014)\end{array}$ \\
\hline Typical Students & 390 & 77.84 & $\begin{array}{l}1.411^{\mathrm{ce}} \\
(0.025)\end{array}$ & $\begin{array}{l}-0.017^{\text {се }} \\
(0.0004)\end{array}$ & $\begin{array}{l}1.301^{\mathrm{ct}} \\
(0.003)\end{array}$ & $\begin{array}{l}-0.0004^{c t} \\
(0.0001)\end{array}$ \\
\hline
\end{tabular}

Note:

The numbers in the parentheses are standard errors for the intercept and slope estimates.

All of the above estimates are significantly different from 0.

Within each column, pairs with same superscripts indicate statistically significant differences at $\mathrm{p}<.05$ 
Table 4.

Logit Coefficients and Odd Ratios for Two-Class Model of Bullying and Victimization

\begin{tabular}{|c|c|c|c|c|c|c|c|c|}
\hline & \multicolumn{4}{|c|}{ Bullying } & \multicolumn{4}{|c|}{ Victimization } \\
\hline & Logit & SE & t-value & Odd & Logit & SE & t-value & Odd \\
\hline & & & & Ratios & & & & Ratios \\
\hline Band 2 School & 0.357 & 0.450 & 0.794 & 1.429 & -0.349 & 0.544 & -0.642 & 0.705 \\
\hline Band 3 School & 0.686 & 0.396 & 1.730 & 1.984 & $1.266^{* *}$ & 0.460 & 2.754 & 3.546 \\
\hline Gender (F) & $-1.517 * * *$ & 0.407 & -3.729 & 0.219 & $-1.343 * * *$ & 0.399 & -3.368 & 0.261 \\
\hline Relatedness & $-0.523 *$ & 0.231 & -2.269 & 0.593 & $-0.749 * * *$ & 0.221 & -3.396 & 0.473 \\
\hline Autonomy & 0.217 & 0.280 & 0.774 & 1.242 & -0.485 & 0.361 & -1.344 & 0.616 \\
\hline Competence & -0.198 & 0.335 & -0.592 & 0.820 & 0.465 & 0.423 & 1.100 & 1.593 \\
\hline
\end{tabular}

Note:

${ }^{*} \mathrm{p}<.05 * * \mathrm{p}<.01 * * * \mathrm{p}<.001$ 
Table 5.

Post-hoc Analyses for Latent Class Membership by School \& Gender

\begin{tabular}{lccccc}
\hline $\begin{array}{l}\text { Latent Class } \\
\text { Membership }\end{array}$ & $\begin{array}{l}\text { Band 1 } \\
\text { School }\end{array}$ & $\begin{array}{l}\text { Band 2 } \\
\text { School }\end{array}$ & $\begin{array}{l}\text { Band 3 } \\
\text { School }\end{array}$ & Male & Female \\
\hline Bully-victims & $4.1 \%$ & $4.6 \%$ & $18.9 \%$ & $16.8 \%$ & $2.4 \%$ \\
Bullies & $6.2 \%$ & $14.4 \%$ & $8.6 \%$ & $15.2 \%$ & $4.4 \%$ \\
Victims & $1.4 \%$ & $1.1 \%$ & $6.5 \%$ & $3.2 \%$ & $2.8 \%$ \\
Typical Students & $88.3 \%$ & $79.9 \%$ & $65.9 \%$ & $64.8 \%$ & $90.4 \%$ \\
\hline
\end{tabular}

Note:

There was a significant association between school and class membership: $\chi^{2}=46.846, d f=6$, $\mathrm{p}<.001$

There was a significant association between gender and class membership: $\chi^{2}=52.501, d f=3$, $\mathrm{p}<.001$ 
Table 6.

Post-hoc Comparisons of Scores of SDT Indicators at T1 by Latent Class Membership

\begin{tabular}{llll}
\hline Latent Class Membership & Relatedness & Autonomy & Competence \\
\hline Bully-Victims & $3.118^{\mathrm{ac}}$ & 2.837 & 2.781 \\
& $(.799)$ & $(.764)$ & $(.799)$ \\
Bullies & $3.572^{\mathrm{a}}$ & 2.984 & 2.918 \\
& $(1.017)$ & $(.825)$ & $(.829)$ \\
Victims & 3.419 & 2.667 & 2.989 \\
& $(1.008)$ & $(.877)$ & $(.580)$ \\
Typical Students & $3.797^{\mathrm{c}}$ & 2.817 & 2.826 \\
& $(.715)$ & $(.845)$ & $(.770)$ \\
\hline
\end{tabular}

Note:

Overall, there were significant differences on perceived teacher support in relatedness $(F=$ 12.660, $d f(3,496, \mathrm{p}<.001)$ between the four classes.

Within each column, pairs with the same superscripts indicate significant differences at $\mathrm{p}<.05$ 


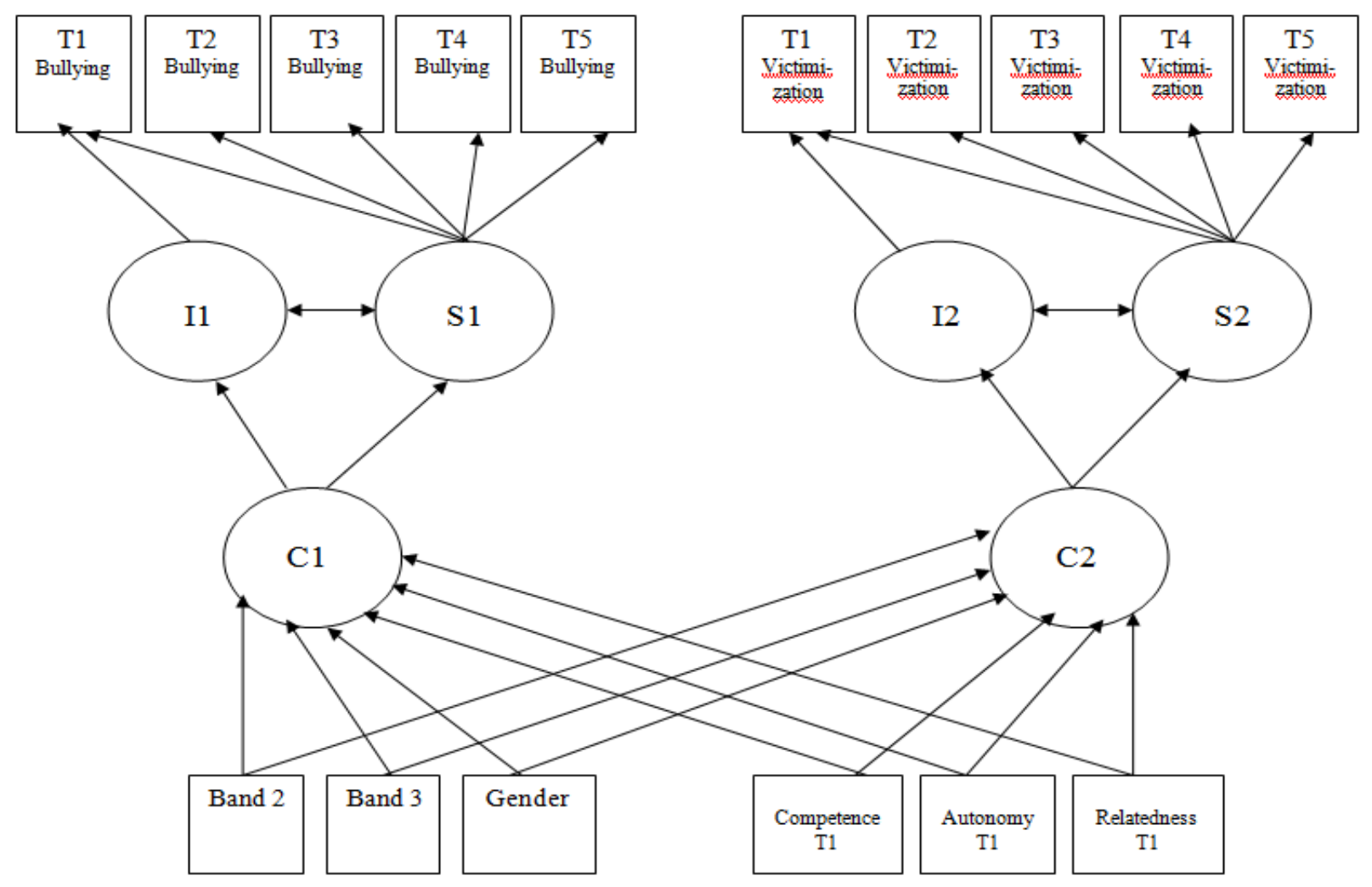

Figure 1. Parallel latent class growth model of bullying and victimization throughout the junior secondary school years. 

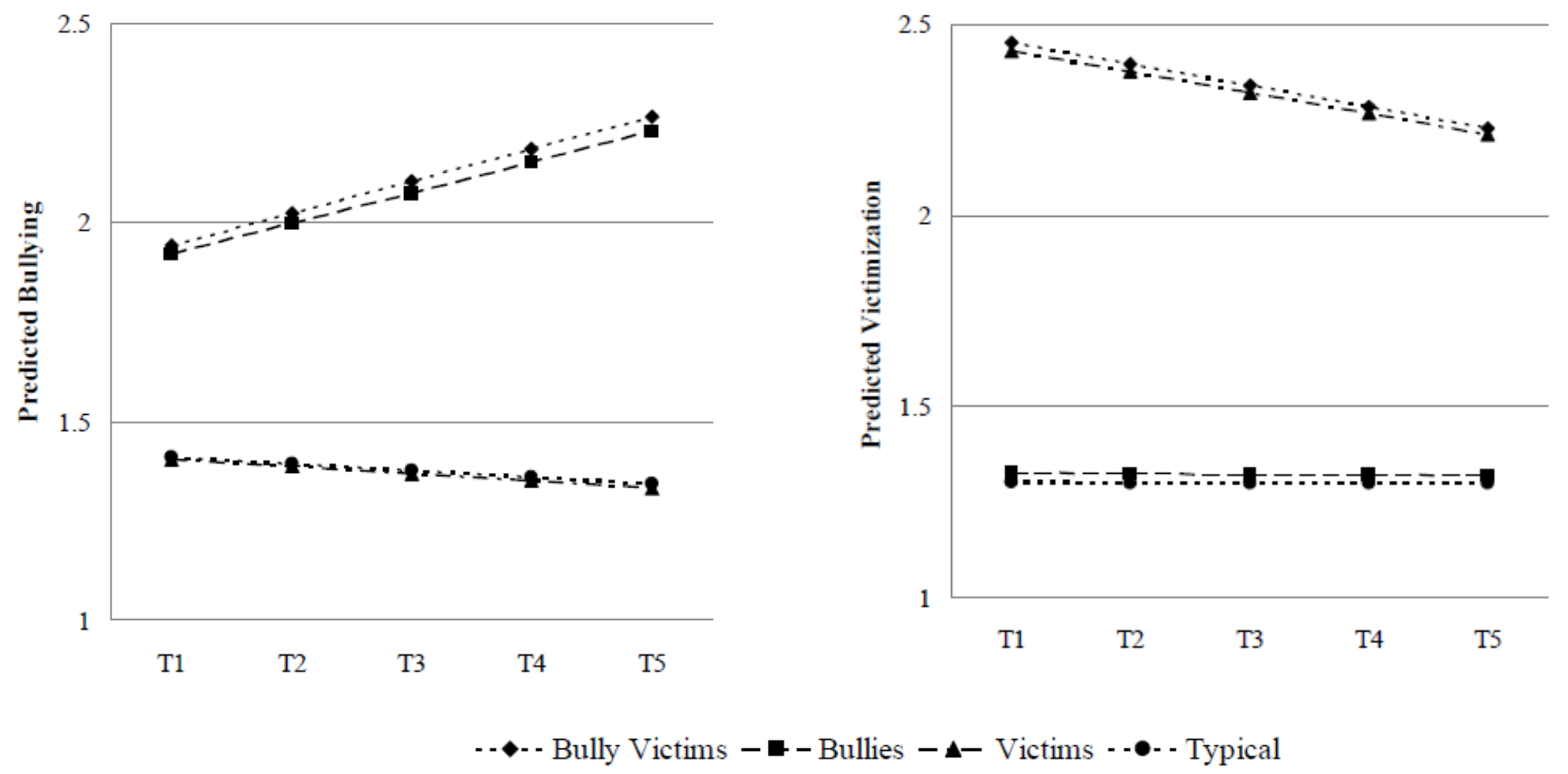

Figure 2. Predicted bullying and victimization trajectories by class membership. 